\title{
Cuando la alteridad es mediada: una experiencia etnográfica sobre las relaciones entre cientistas sociales, movimientos indígenas y Estado(s)
}

\author{
ALDANA CALDERÓN ARCHINA \\ Consejo Nacional de Investigaciones Científicas y Técnicas, Argentina \\ aldana_c03@hotmail.com
}

DOI 10.11606/issn.2316-9133.v29i2pe168123

resumen En este artículo abordaré situaciones etnográficas acontecidas en el marco de un curso/taller sobre "fortalecimiento identitario", a cargo de profesionales no indígenas para jóvenes de una comunidad huarpe de la provincia argentina de San Luis. Me interesa desentrañar el complejo de relaciones entre profesionales de las ciencias sociales, movimientos indígenas y agentes estatales. Sobre esta base, presentaré una serie de reflexiones acerca de los desafíos que surcan estos movimientos, teniendo en cuenta su reciente de institucionalización y reconocimiento estatal. El propósito final está en discutir acerca de cómo abordamos la etnicidad y las representaciones de alteridad quienes indagamos sobre este tipo de procesos, ante el peligro de asentar la otredad como hecho.

palabras clave Estado. Movimientos indígenas. Alteridad. Ciencias sociales.

When otherness is mediated: an ethnographic experience on the relations between social scientists, indigenous movements and state(s)

abstract This article analyzes ethnographic situations in a course about "identity strengthening", dictated by non-indigenous professionals to young people from a Huarpe community in San Luis, Argentine. The purpose is to unravel the complexities of relationships between social scientists, indigenous movements, and state agents. Thereby, it presents some thoughts about the challenges faced by indigenous movements, after their recent process of institutionalization and state recognition. The final aim is to discuss how otherness and ethnicity is approached by anthropologists who investigate these processes, because of the danger of establishing otherness as a fact.

keywords State. Indigenous movements. Otherness. Social scientist. 


\section{Quando a alteridade é mediada: uma experiência etnográfica sobre as relações}

\section{entre cientistas sociais, movimentos indígenas e o(s) Estado(s)}

resumo Neste artigo vou abordar situações etnográficas no âmbito de um curso sobre "fortalecimento da identidade", ministrado por profissionais não indígenas a jovens de uma comunidade Huarpe, na província argentina de San Luis. Estou interessado em desvendar o complexo de relações que foram articuladas neste evento, em particular as ligações construídas entre cientistas sociais, movimentos indígenas e agentes estatais. Desta forma, presentarei uma série de reflexões sobre as posições que assumimos como parte da tarefa antropológica, especialmente em uma situação que apresenta sérios desafios a estes movimentos, após ter passado por um processo relativamente recente de institucionalização e reconhecimento. $O$ propósito final é discutir como a etnicidade e as representações de alteridade são abordadas por antropólogos que investigam esses processos, tendo em vista o perigo de estabelecer a alteridade como um fato.

palavras-chave Estado. Movimentos indígenas. Alteridade. Cientistas sociais.

\section{La apuesta por lo incómodo}

Quienes realizamos labor de campo etnográfico, acuñamos la práctica de registrar la mayor cantidad de información que esté a nuestro alcance. En ese cúmulo de anotaciones también hallamos experiencias que se imbrican al terreno de lo inesperado. Pues, quedar expuestos a distintos tipos de intensidades sensoriales y/o afectivas, resulta inevitable. Aun así, la confusión y/o perplejidad que ello puede causarnos, no suele traspasar las hojas del diario de campo, ¿será que no estamos acostumbrados -preparados- a escribir desde la vergüenza o el enojo? Aunque si dijera que la situación que aquí trataré versó en un suceso repentino o fortuito, sería incorrecto. Principalmente porque decidí participar de este evento, sin perjuicio de que ello haya anulado mi incómoda perplejidad. Decido retomar una situación que había relegado a lo anecdótico, para hacer algo con lo que incomoda y, hasta avergüenza, parodiando a Deleuze (1995). Una vergüenza que el autor une a la condición humana y que considera como impulso, motivo de creación y liberación de las jaulas (ético-metodológicas) que fabricamos.

Concretamente la serie de hechos que abordaré tuvieron lugar en una comunidad indígena huarpe con la que trabajo desde hace algunos años. ${ }^{1}$ La misma se encuentra en un paraje rural en el noroeste de la provincia argentina de San Luis. ${ }^{2}$ En una oportunidad viajé para asistir al " 10 taller de fortalecimiento identitario" dictado por un grupo de profesionales de las

\footnotetext{
1 En el año 2014 comencé a realizar trabajo de campo etnográfico en el marco del trabajo final para alcanzar el título de grado en Antropología. La experiencia etnográfica que aquí trataré se desprende del trabajo realizado como parte de mi proyecto de doctorado, donde investigo sobre las relaciones entre organizaciones indígenas y el gobierno de la provincia de San Luis.

2 San Luis es una provincia que pertenece a la región de Cuyo (centro oeste argentino). Los huarpes conforman un grupo étnico prehispánico que se encuentra distribuido en el territorio de los actuales estados provinciales de Mendoza, San Juan y San Luis.
} 
ciencias sociales para los más jóvenes. Desconocía su contenido, pero su llamativo título bastó para despertar mi interés y motivarme a asistir. Mis pruritos éticos se vieron comprometidos al ver que se convocaba a un curso/taller donde un grupo de profesionales universitarios (entre estos antropólogos) instruirían sobre la identidad huarpe, ¡a los proprios huarpes!

En el 'estar ahí' (MALINOWSKI 1986 [1922]) me sentí incomoda e interpelada desde mi lugar de antropóloga. In situ no supe cómo abordar crítica y estratégicamente la situación, no estaba segura sobre cómo actuar y hasta qué punto involucrarme en las discusiones de un taller realizado por otros profesionales en mí misma área de estudio. Opté por observar y registrar todo lo posible, realicé algunas breves intervenciones. Después de un tiempo decido retornar a aquella situación para analizarla con el objeto de comprender, desentrañar y objetivar los acontecimientos vivenciados, y con la finalidad última de alcanzar una discusión que profundice sobre la relación entre cientistas sociales -con acento en los provenientes o afines al campo de la antropología- y movimientos indígenas. También haré hincapié en quienes asumen el rol de portavoces de comunidades indígenas y que cumplen funciones de mediadores entre las comunidades y el estado (provincial y/o nacional). Especialmente en una coyuntura que presenta serios desafíos a los actores indígenas tras haber alcanzado el reconocimiento estatal, y luego de atravesar un proceso relativamente reciente de institucionalización.

Comenzaré por contextualizar la emergencia indígena de movimientos huarpes en las últimas décadas, con énfasis en San Luis, junto con un breve análisis de la política de reconocimiento indígena del estado provincial. Luego pasaré a narrar los hechos que presencié en el taller para posteriormente abocarme a los puntos de análisis que mencioné más arriba. Por último, realizaré una reflexión desde mi lugar como antropóloga situada respecto de la relación entre cientistas sociales e indígenas en cuanto a las formas de abordar y construir alteridad(es). En tal sentido, este trabajo es también un intento por derribar ciertas construcciones edulcoradas respecto de lo indígena (ESCOLAR 2010).

\section{La cuestión indígena en San Luis}

La comunidad huarpe fue la primera en darse a conocer públicamente en la provincia, este colectivo nuclea tres grupos familiares extensos (aproximadamente sesenta personas). Se constituyeron como comunidad en 2006, año en que solicitaron la personería jurídica ante el Instituto Nacional de Asuntos Indígena (INAI). ${ }^{3}$ Se autoreconocen como descendientes del pueblo huarpe que habita en el centro oeste argentino desde antes de la época colonial. Más puntualmente de los huarpes laguneros, denominados así por su permanencia en el complejo palustre de Guanacache, conformado por ríos originados en la Cordillera de los Andes. El cual comenzó a sufrir un proceso paulatino de desecamiento a comienzos del siglo XX, esto afectó las condiciones de vida ocasionando la migración de una parte considerable de la población hacia zonas irrigadas. Por tal motivo, es que previo al proceso de agrupamiento e

3 Conforme a lo establecido por la Ley nacional 23.203, el estado nacional, a través del INAI, reconoce la filiación de sus integrantes con poblaciones preexistentes al Estado argentino. Por consiguiente, si cumplen con una serie de requisitos, obtienen la figura jurídica de personería comunitaria. 
institucionalización, estas familias se encontraban dispersas en zonas rurales y urbanas cercanas a donde habitan en la actualidad.

Desde hace aproximadamente una década, residen dentro del territorio comunal restituido por el estado provincial como parte de la "politica de reparación histórica para con las culturas originarias de San Luis”. Esta medida surgió en una coyuntura de mayor visibilidad pública de los grupos indígenas a nivel nacional y como parte de un 'estallido de mapas étnicos' (ESCOLAR 2007). Concretamente en San Luis asistimos un proceso reciente de emergencia indígena que se tornó más palpable en la última década. Es bastante joven comparado a otras provincias del país, ya que en la mayoría de ellas las demandas de estos colectivos irrumpieron en la década de 1990. Respecto de la política indigenista provincial, también es relativamente nueva y no atañe por igual a todas las comunidades, familias y personas que se autoreconocen como indígenas y/o descendientes. De hecho, abarca únicamente a esta comunidad huarpe y a otras dos ranqueles.

Sucintamente podemos referir a algunas características de la política implementada desde 2006/2007. La misma se estableció en sintonía con tratados internacionales y legislación nacional sobre derechos indígenas, comprende acciones concretas de carácter "reparador" ante los daños acometidos históricamente contra estos pueblos. La restitución de parte del territorio ancestral resultó acompañada de la construcción de viviendas, escuelas y hospitales, más la entrega de planes sociales. Otro aspecto a resaltar es el otorgamiento, mediante decreto, de un estatus de autonomía equiparable a la de un municipio con el objeto de posibilitar la autodeterminación. De modo que eligen a sus propias autoridades (cacique/lonko), encargadas de administrar los fondos otorgados por el gobierno provincial. No menos importante fue la instauración de una oficina de asuntos indígenas en la administración pública provincial, a cargo durante varios años de Juana, integrante y referente de la comunidad huarpe.

Lo anterior nos habla de las especificidades en el modo en que fue ejercido el reconocimiento estatal hacia un otro indígena en San Luis, que en términos históricos implicó un cambio sustancial en la relación entre estado provincial e indígenas, tras años de negación/invisibilización (CALDERÓN ARCHINA 2016). No obstante, el impacto sobrevino no tanto en la sociedad en general como en quienes fueron acogidos dentro de esta política, ocasionando cambios significativos en su cotidianeidad. Como, por ejemplo, su relocalización: familias numerosas pasaron de vivir en viviendas de adobe, a residir en casas de material con servicios básicos, y en número reducido de habitantes. Además, se trata de una zona fronteriza en el límite tripartito con las provincias de Mendoza y San Juan, donde actualmente residen comunidades y personas autoreconocidas como huarpes y en un territorio históricamente considerado como "desierto" -marginalizado espacial, cultural y económicamente-. De modo que la transformación del paisaje con la construcción de toda la infraestructura (viviendas, escuela, etc.), marcó una considerable delimitación entre quienes quedaron "dentro" del territorio restituido y quiénes no.

Cabe expresar que esta política indigenista se inserta en una coyuntura de consolidación de políticas de reconocimiento a poblaciones indígenas en el terreno de la multiculturalidad neoliberal (HALE 2002). Estos proyectos culturales, políticos y económicos no operan sobre el vacío, la forma en la que irrumpen en contextos locales se haya intrínsecamente vinculada a 
procesos propios y específicos de cada lugar. En este sentido es que coincido con Briones, respecto de pensar en las transformaciones de las geografías estatales de inclusión y exclusión de la diversidad interior, sin pasar por alto los niveles provinciales de estatalidad anidados. Es a través de estos que podemos explicar las variaciones en la organización y demanda de un "mismo" pueblo indígena según las distintas provincias en que se encuentra (2005: 17, comillas del original).
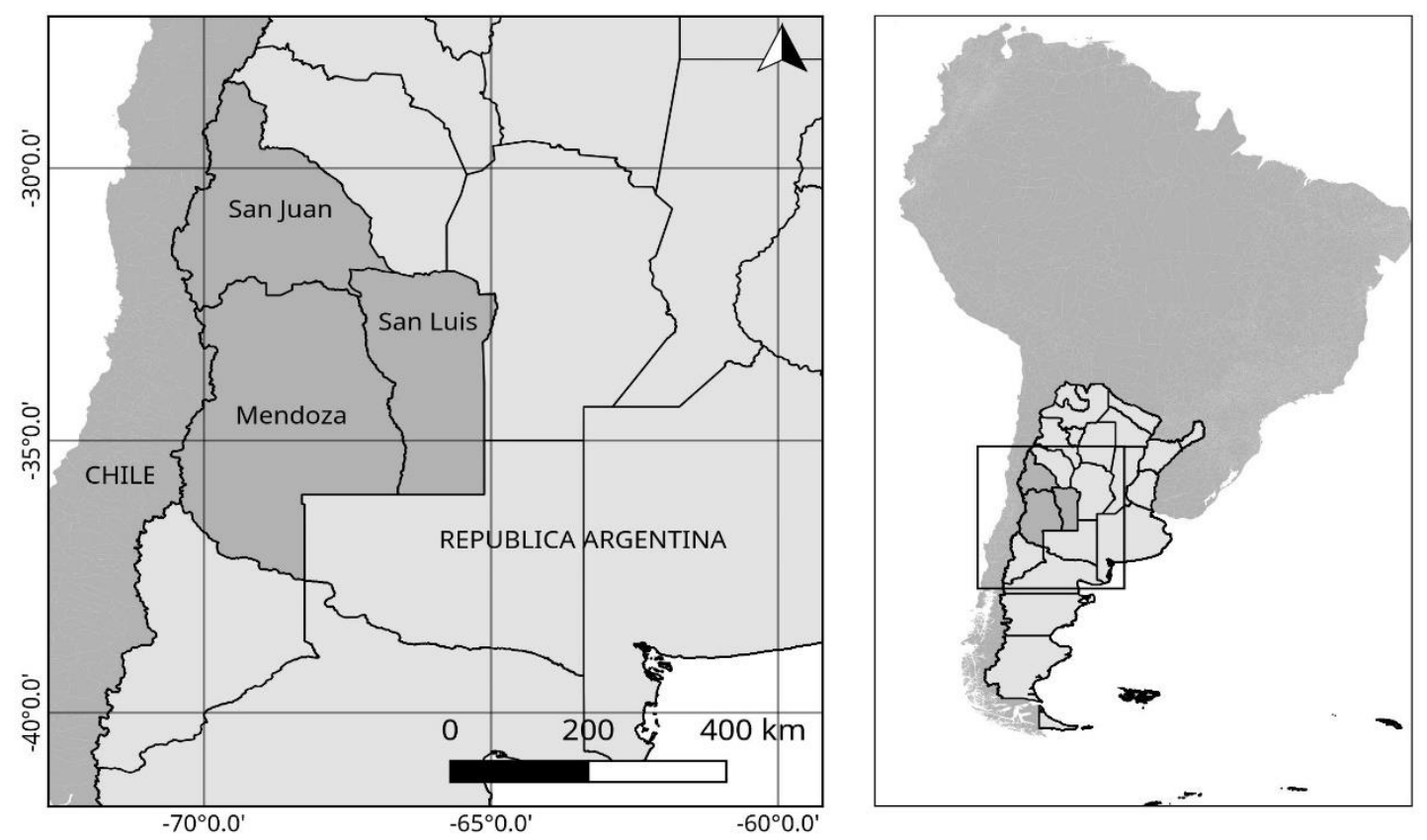

Figura 1. Mapa región de Cuyo, Argentina. Elaborado por L. Alvarez (IANIGLA/CONICET) en base a datos del Instituto Geográfico Nacional.

\section{Huarpes y un pasado de intermediarios}

En marzo de 2017 me enteré, a través de mi página de Facebook, que en una comunidad huarpe ${ }^{4}$ se realizaría el "10 curso de fortalecimiento identitario" destinado a sus jóvenes (hasta treinta años) y organizado por miembros de un programa de extensión universitaria. Como adelanté, esto despertó mi atención y seguidamente me comuniqué por teléfono con la cacique de la comunidad, Juana, quien me invitó a participar del mismo como asistente.

La historiadora/antropóloga encargada de dar el taller, a quien llamaré Claudia, ha trabajado durante muchos años con comunidades huarpes que residen en la provincia vecina de Mendoza. Durante la década de 1990 formó parte del grupo de apoyo del equipo eclesiástico católico (ENDEPA $)^{5}$ articulado a la Pastoral Aborigen Latinoamericana. Ellos siguieron activamente a once grupos huarpes de Lavalle (Mendoza) en el proceso de organización comunal y territorial. La presencia de este organismo no es novedad y no puede pasar

\footnotetext{
4 Dado que cuento con los permisos correspondientes para trabajar con las comunidades mencionadas, sus nombres serán conservados. No así los de las personas involucradas, por decisión de la autora.

5 Concretamente el ENDEPA es un organismo dependiente de la Conferencia Episcopal Argentina que cuenta con presencia en tres regiones del país (NEA, NOA y SUR).
} 
desapercibida, dado que integrantes de grupos católicos, en articulación con académicos y educadores, han ocupado -y ocupan- un rol destacado al interior de movimientos indígenas, inclusive marcando y conduciendo las demandas en distintos puntos de Argentina ${ }^{6}$.

Paralelamente, comenzó a gestionarse un espacio abocado al "diálogo interreligioso" y "pluricultural” en una universidad nacional. En 2006 se oficializó como programa de extensión, Claudia es la encargada del área sobre educación intercultural en poblaciones huarpes y diaguitas. Este programa funciona en San Juan con la intención de articular con grupos indígenas de Mendoza y San Luis, objetivo que se une directamente a su llegada a la comunidad de Guanacache. En otras palabras, este taller fue el primer intento de formalizar el acercamiento de este grupo al territorio huarpe en San Luis. Meses antes, en ocasión de una festividad, coincidimos con Claudia en la comunidad y fue allí donde comenzaron las tratativas entre ella y Juana. Por entonces nos conocimos y me mencionó su trabajo en la universidad, por lo que me llevó un tiempo, luego de transcurrido el curso/taller, asociar su trabajo al del grupo religioso ${ }^{7}$.

Para el caso de los huarpes que habitan en San Luis, es menor la cantidad de profesionales que han trabajado/investigado en relación a estos grupos, si se compara con las provincias vecinas $^{8}$. Como tampoco se registra presencia de organizaciones religiosas en este territorio, al menos en los últimos años. Al indagar sobre sus trayectorias y la etapa de organización, pude conocer algunas de las dificultades que atravesaron al momento de constituirse como colectivo. Mis interlocutores manifestaron el haber sentido miedo y desconfianza respecto de que la situación pudiese revertirse para mejor y, por tales motivos, algunas personas dudaron sobre su participación. Por entonces lo alcanzado era inimaginable, de hecho, fue la problemática por el agua que los movilizó y acercó al gobierno. Durante el diálogo con las autoridades, en particular con el gobernador, surgió lo venidero en materia de reconocimiento.

Pero una vez superada aquella instancia de vacilación, y luego de constituirse y de ser reconocidos como comunidad originaria, otras cuestiones comenzaron a asomar. Quienes ejercen -o ejercieron- algún cargo de autoridad, aluden que tras estos cambios se fue debilitando el interés y compromiso en cuestiones que atañen a la vida en comunidad. Precisamente el objetivo del curso iba por ese lado, tal fue la respuesta que Juana me brindó antes de que llegaran los profesores aquel día: "dada la falta de interés de la gente, acudí a profesionales".

La contextualización realizada da cuenta de los espacios de emergencia que irrumpieron en la arena pública, articulados a las trasformaciones y condicionamientos sobrevenidos en materia de políticas indigenistas y efectos de reconocimiento. Pero también, nos sirve para comprender la coyuntura donde asoman replanteos y desafíos en torno al porvenir. Justamente,

6Trabajos antropológicos que abordan la presencia de ENDEPA en Cuyo: Escolar (2010) y Saldi (2012); para el NOA ver: Espósito (2017).

7 Diego Escolar (2010) analiza el papel que tuvieron actores del campo religioso y educativo durante el proceso de institucionalización de grupos huarpes en Mendoza y la lucha por su representación.

$8 \mathrm{El}$ hecho de que existan mayor cantidad de trabajos de investigación sobre el pueblo huarpe que habita en San Juan y Mendoza, guarda relación con que los procesos de reivindicación indígena en San Luis son recientes y abarcan a un grupo menor de personas. 
estos son los motivos que dieron lugar al taller. Las autoridades de la comunidad se encuentran preocupadas respecto de cómo seguir y por cómo reavivar el interés de sus integrantes, manteniendo la legitimidad de las conquistas obtenidas. Es entonces que (re)aparece este grupo de profesionales.

\section{Día uno: Taller de fortalecimiento identitario: ¿Para qué? ¿Para quienes?}

El taller tuvo una duración de dos días, viernes por la tarde y sábado hasta el mediodía. En cuanto al financiamiento, la comunidad huarpe dispuso de las instalaciones de la escuela y brindó alojamiento gratuito a los profesores en las viviendas destinadas al turismo. Por lo que pude percibir en conversaciones con Claudia, el traslado corrió por cuenta del propio equipo. Desconozco si recibieron una paga extra los docentes, por parte de la comunidad.

En mi caso, llegué la mañana del viernes y me alojé en la casa de Juana donde vive junto a su marido, una vivienda social ubicada dentro del territorio comunitario. Los profesores llegaron horas más tarde, Claudia era la mayor de un grupo de cuatro, el resto son profesionales de treinta años aproximadamente. Aún en casa de Juana, Claudia le dice a ella: "armamos todo en función de tu pedido", entonces aproveché para preguntar por qué decidieron realizar un curso destinado a los jóvenes y no a toda la comunidad. Claudia, algo a la defensiva, me contestó: "porque eso nos solicitó Juana, un curso para los más jóvenes y otro para los adultos, que será más adelante". Juana intervino y argumentó que la división en grupos etarios se debía a que se requieren otras formas de aprender, entonces consideró más pertinente dividir y comenzar por los jóvenes.

Al cabo de unos minutos fuimos hasta la escuela, ubicada a pocos kilómetros y próxima a la tranquera de acceso. Algunos estudiantes esperaban en la puerta, ingresamos y acomodamos los bancos, Claudia pidió que de ser posible se colocaran los pupitres en semicírculo. También colgaron afiches y repartieron folletos, ambos realizados y financiados por ENDEPA. En total asistieron siete jóvenes de una edad aproximada de once a trece años, todos estudiantes de la escuela huarpe pero solo tres de ellos residen dentro del territorio comunal. El resto vive en localidades aledañas, ergo, no son miembros de la comunidad de Guanacache. La única mayor de edad fue Lorena, sobrina de la cacica Juana y ordenanza de la escuela. En las últimas horas de la primera jornada, se sumó una pareja de profesores, miembros de la comunidad.

Claudia fue la encargada de comenzar, contó que tiene un amigo quechua que le enseñó que los indígenas se organizan mediante la forma del círculo y no en estructuras jerárquicas. Por tal motivo, dispuso de los pupitres en forma de círculo. Paradójicamente, ella se mantuvo al frente, de pie y presidiendo:

C: ¿Saben cómo se llama el curso? Curso de fortalecimiento identitario. A ver... piensen: fortalecimiento, ¿De dónde les suena?,

\footnotetext{
9 Finalmente, el taller destinado a los adultos, no se dictó por problemas personales de la profesora a cargo.
} 
Un joven contesta: de fortalecer.

[Se produce un silencio]

C: Es lo necesario para que esté más fuerte, en este caso la identidad. La identidad tiene que crecer con más fuerza (...)

Entonces, vamos a ver los instrumentos con los que pueden fortalecer la identidad.

[Como el profesor siguiente continuaba con los preparativos, Claudia siguió hablando]

C: Voy a contar un poquito sobre cómo fue el proceso de organización de las comunidades huarpes en Mendoza. ¿Tienen parientes? ¿Conocen cómo fue que se organizaron?

Lorena: Sí.

C: A ver Lorena...

L: Mucho no conozco, solamente sé que ellos tienen muy pocos recursos, entonces tienen muchos problemas para que los reconozcan como nos reconocieron a nosotros y por eso están en la lucha.

C: Muy bien. Es verdad. Ella ha hecho una preciosa síntesis.

En este preludio, Claudia introdujo el trayecto recorrido junto a los huarpes mendocinos. Presentó a estas comunidades como un caso modelo de lucha, postuló que el reconocimiento de derechos por parte del estado de Mendoza no es pleno ${ }^{10}$ y que las conquistas alcanzadas son principalmente el resultado de la unión y fuerza de estas once comunidades. Y de una forma sutil refirió al trabajo de "acompañamiento" realizado por grupos religiosos, inclusive remontándose a la época colonial con la presencia de los jesuitas. Posteriormente fue cediendo la palabra a los distintos profesores, quienes hicieron una presentación afín a sus temas de estudio. Pedro, profesor de geografía, se ocupó de mencionar las comunidades huarpes de San Juan según la distribución geográfica y tipo de organización; y Sandra, profesora de historia y maestranda en antropología, se encargó de exponer los alcances en materia de legislación indigenista.

Juana (cacica) intervino para manifestar su disconformidad ante la baja concurrencia, lamentando que quienes integran la comunidad no acudan a este espacio, como mencioné fueron únicamente tres miembros. Y, en relación con lo dicho por Claudia sobre la historia del pueblo huarpe y el avasallamiento durante la época colonial, ella agregó:

Esta comunidad y estas familias, que descienden de aquel gran pueblo, tuvieron una etapa de mucha injusticia. Entonces, el gobierno de San Luis,

10 En general, podemos aludir los conflictos por tenencias y restitución de tierras, amenazas de expropiación y falta de cumplimento en los acuerdos pactados. Para más información ver los trabajos ya citados para la zona. 
en un acto de justicia para devolver parte de lo que se quitó, es que ha devuelto tierras y se han construidos viviendas y esta escuela.

Los jóvenes que asistieron no intervinieron demasiado, lo hacían tras la insistencia de Claudia o Juana. Si bien los profesores dieron lugar en sus exposiciones a preguntas, quienes mayormente arbitraron la conversa fueron los adultos. Uno de los principales sobresaltos se produjo luego de la presentación del profesor Pedro, él habló sobre las distintas comunidades que residen en San Juan. Fue entonces que, con cierta timidez, Juana indagó sobre una de las comunidades del listado y, progresivamente, se debelaron dobleces que existen entre organizaciones. El punto más álgido aconteció luego de que el profesor mencionó a los pinkanta, una organización bastante numerosa que nuclea a huarpes que residen en San Luis y en San Juan, y con la que existe cierta disputa que involucra diferencias en los criterios de conducción así como altercados por recursos económicos. Los asistentes quedaron fuera de la discusión y por momentos atónitos, al igual que los otros profesores. Pedro, al parecer, desconocía estas internas y optó por mantenerse al margen de la conversación que protagonizaron Claudia y Juana y, en menor medida, Lucrecia, profesora de la escuela huarpe ${ }^{11}$. Claudia planteó que en esta organización se pone en relieve un uso instrumental del poder político, cuyos dirigentes ocupan cargos estatales (como en el Consejo Provincial Indígena) desde donde tejen alianzas con organismos estatales; volvió a colocar como contrapunto a las comunidades mendocinas. Ante el despliegue de Claudia, que duró unos cuantos minutos, Juana manifestó: "ahora entiendo". Recordemos que ella introdujo la discusión tras insinuar cierta incomprensión, puede que más bien haya optado darse por eludida como una forma de deslegitimar los criterios de organización del grupo. Baso esta argumentación en la rivalidad que existe entre los grupos (de Guanacache y los pinkanta) y en particular entre sus referentes. El punto de quiebre de esta relación se produjo cuando solo una de estas comunidades fue reconocida por el gobierno sanluiseño, siendo que ambas comenzaron a reivindicar su identidad como huarpes casi en simultáneo. Si bien públicamente no se ha producido un conflicto, implícitamente no hay buena relación.

Por cómo se fue desatando esta conversación, vemos que lo que entra principalmente en pugna son los medios y formas a través de los cuales cada organización se fue erigiendo, los caminos que siguieron, los espacios por los que circulan, qué y cómo reclaman, así como ante quienes lo hacen y los recursos en juego. Además, lo anterior se suma a la presencia de "nuevos" interlocutores (este grupo de profesionales universitarios) frente a los cuales Juana debía posicionarse desde su lugar de referente indígena, y como funcionaria estatal. En tal sentido, un aspecto crucial a tener en cuenta son los lugares de enunciación desde donde fueron legitimados los posicionamientos.

\section{Derroteros de la primera jornada}

11 La dirección y los contenidos de la escuela dependen del Ministerio de Educación provincial y de una universidad provincial. El equipo docente está conformado mayoritariamente por profesores externos no indígenas que viajan desde la ciudad capitalina. 
Aquel primer día finalizó con la presentación de Sandra. Ella se encargó de presentar los alcances en materia de derechos indígenas y mencionó normativas relativas para el caso de San Luis. En más de una oportunidad aclaró que su área de estudio está en San Juan por lo que desconocía practicante la situación jurídica de los pueblos indígenas en San Luis, salvo por el material que consultó los días previos. En consecuencia, en la exposición buscó constantemente la aprobación de Juana y, por momentos, directamente le consultó a ella, cuyas repuestas se orientaron a enaltecer la postura del gobierno provincial, inclusive hasta justificarla.

En los años que trabajo con Juana, ella siempre se ha posicionado como representante indígena sin descuidar su lugar de funcionaria del gobierno provincial. Una praxis que fue adquiriendo al ocupar un cargo dentro la administración pública desde hace más diez años. Por ende, está acostumbrada a transitar y desenvolverse en ámbitos estatales como en encuentros presididos por organizaciones indígenas, ha recibido reconocimientos de organismos nacionales e internacionales por su labor. La conciliación entre ambos roles se ve reflejada constantemente en su oratoria, a través de la cual tiende a subrayar el "noble" accionar del estado provincial para con los indígenas. Comentarios similares incurrieron en las últimas horas de ese día, por ejemplo, cuando compartió algo que le sucede a menudo ante indígenas de otras provincias: "Me pasa que cuando cuento cómo es la organización y cómo es la relación que tenemos con el gobierno de la provincia, a la gente le suena como un cuento de hadas... ¡Pero es verdad lo que nosotros contamos!".

Claudia agregó que se trata de una "situación de privilegio" con relación a otros indígenas del país y subrayó que aquello es posible gracias a la intención del gobierno provincial, "son el caso modelo del país", determinó. A sazón de estos últimos sucesos, planteé que el Estado de San Luis no le otorgaba "beneficios", como si fuese un mero acto de beneficencia, desinteresado, que en todo caso mejor habláramos de reconocimiento de derechos. Si bien no se objetó mi comentario, no implicó que necesariamente acordaran. Como podrá verse a la luz de otras escenas, prevaleció una noción de estado asistencialista, como ente encargado de suministrar recursos, materializado a través de distintas agencias y agentes.

Lo anterior refleja una situación, entre otras, en la que me sentí interpelada y en duda respecto de cómo actuar. En general, no coincidía con lo que se planteaba y en especial en la forma en que lo hacían. Nuestros posicionamientos eran distintos, ‘hubiese sido posible establecer un diálogo desde la discrepancia? Por entonces creí que no. Desde el inicio pude notar el condicionamiento que produjo mi presencia por momentos, como cuando interrogué sobre la delimitación etaria del curso y Claudia me marcó que así fue solicitado por la cacica. En otras oportunidades buscaron valorizar mi opinión como conocedora del lugar. Con esto quiero decir que no es que se haya transformado en un problema de autoridad o de competencias, sí en algún momento percibí que así lo fuera, no fue más que una mala lectura. Probablemente nublada por la incomodidad que sentí, llegué a incurrir en un "deber ser" de lo que esperaba de otro antropólogo, por ejemplo, cuando intercedí respecto de cómo pensar las políticas estatales. Me topé ante visiones esencialistas y cierto romanticismo con las comunidades mendocinas, así como los posicionamientos me sonaron acríticos respecto al rol del estado. Esta sumatoria de percepciones y sensaciones limitó mi comprensión sobre los hechos. In situ no pude leer las 
redes y relaciones en las que estábamos insertos. Como trataré más abajo, hubo otros intereses en juego.

Por último, considero que mi confusión fue pensar a este grupo lisa y llanamente como colegas, cuando la discrepancia no se dirimía en términos de trayectorias académicas y enfoques analíticos. En tanto que no fueron convocados por el mero hecho de conformar un equipo que investiga la temática indígena, más allá de que en la presentación del grupo mencionaron únicamente su profesión y temas de investigación, y solo Claudia se definió como antropóloga y militante de la causa indígena. A lo largo de las exposiciones, y mediante el empleo de la retórica y recursos pedagógicos, buscaron dotar de legitimidad su trabajo como aquel que es realizado "con" y "en" comunidades huarpes. Y si bien se invocó al diálogo intercultural como un espacio neutro y despolitizado, veremos que lejos está de serlo. Creo entonces que para poder comprender más cabalmente lo acontecido, es necesario partir de la premisa de que se trató de un espacio inserto en un campo de acción que yuxtapone intermediarios indígenas, agentes sociales y estatales y diagramas de saber/poder.

\section{Gestores (de) indígenas en Cuyo}

Es menester aludir a la anterioridad de estos vínculos. Como anticipé, la presencia de mediadores en la zona de Guanacache se haya relacionada a una experiencia próxima articulada al proceso de institucionalización de las once comunidades mendocinas y, a otra más tardía, que remonta al siglo XIX, cuando los laguneros huarpes acudían a intermediaros "blancos" para gestionar sus demandas que alimentaron vínculos de patronazgo o paternales (ESCOLAR 2010: 196). Asimismo, debemos mencionar las prácticas de evangelización que contribuyeron a crear vínculos de fidelidad y dependencia entre la iglesia y los pobladores de Guanacache durante los periodos de conformación del estado moderno (PRIETO 1998 en SALDI 2012).

Escolar (2010) analizó etnográficamente las luchas por la construcción de la representación política del movimiento huarpe de hace más de una década. En particular el del grupo liderado por un cura que, como dijimos, juntó a sectores religiosos con personal de instituciones educativas -entre los cuales se encontraba Claudia-. Mediante prácticas corporativas y operaciones políticas, los miembros de este grupo se transformaron en portavoces públicos de las comunidades, al punto de constituirse en un aparato de intermediación y de dirección política y discursiva. En consecuencia, y ante el acatamiento por parte de las comunidades, las mismas fueron perdiendo el control de sus acciones y nominaciones discursivas (2010: 177).

Por su parte, Saldi (2012) da cuenta de cómo este grupo de mediadores, además de controlar y distribuir los recursos entre las comunidades (desde ropa hasta becas universitarias), tuvieron una fuerte incidencia al momento de delimitar los criterios acerca de quienes podían o no pertenecer, basándose principalmente en argumentos territoriales. Recordemos que la diáspora es un aspecto característico de la población de la zona, además, quienes debieron migrar no necesariamente abandonaron los lazos de pertenencia ni de alianza con el lugar y sus habitantes. Tal es el caso de Lorenzo y su familia, el Omta (jefe territorial y líder espiritual) de la organización pinkanta, la cual fue parte y motivo de discusión en el taller. Por la década de 1990 quedaron por fuera de las once comunidades, siendo que ellos guardan parentesco de 
segundo grado con quienes sí fueron incluidos, a la vez que los padres de él han pasado toda su vida en el secano (noreste mendocino) en un territorio actualmente disputado por su reconocimiento como comunitario.

Poco tiempo después de transcurrido el taller, Lorenzo mencionó en un encuentro que creía haberme visto en una foto en las redes sociales junto a Claudia. Brevemente le comenté mi experiencia. Tanto a él, como al resto de los presentes, les desconcertó la noticia, principalmente por el hecho de que necesiten de otros no indígenas para trabajar en su identidad. En este último punto, es interesante comparar las tácticas de estos dos grupos, ya que los pinkanta también se han acercado y trabajado en ámbitos estatales, académicos y escolares con el objetivo de reivindicar su identidad huarpe. Ahora bien, tal como lo marcaron ese día, su principio es que sean ellos mismos quienes dirigen la agenda de lucha desmarcándose de los "logos", como suelen referirse a algunos profesionales no indígenas. Además, tomemos en cuenta el vínculo directo entre estos agentes externos y quienes, años atrás, los excluyeron del proyecto institucionalizador de las comunidades huarpes de Mendoza.

En función de lo observado y analizado hasta aquí, pueden postularse una serie de enunciados. Primero, la continuidad de los lazos construidos entre mediadores no indígenas y huarpes. Me baso no tanto en la permanencia de una integrante -eso implicaría reducir un entramado complejo de relaciones a una sola persona-, si no, más bien porque considero que lo presentado revela la pugna continua y renovada en la construcción de identidades, hacia dentro y fuera de la organización huarpe, como en el lugar que en ella ocupan los sectores académicos. Segundo, la controversia sobre los distintos modos de entender la política indígena puso en evidencia los distintos sentidos en torno a lo político y cómo esto se entrama a las disputas entre organizaciones y los modos que cada una concibe el hacer política y las estrategias de las que se valen. En el caso de Juana, debe considerarse que ocupa un lugar liminar y distinto de otros líderes indígenas, en su decir encarna al Estado. Tercero, la actuación del grupo de profesionales puede leerse como la de intermediaros o 'brokers' que disponen de un 'saber-hacer' (BASCOPÉ 2009: 48) sobre cómo la identidad debe ser practicada. Y en este trasfondo puede comprenderse la utilización del término "beneficios", en tanto que su empleo remite a la labor de estos intermediarios como facilitadores y/o proveedores de bienes, servicios e influencias (ESCOLAR 2010). Su labor, como toda prestación, requiere de su redistribución y en este caso es la lealtad para con ellos, habilitando el ingreso a otro territorio provincial.

Para concluir con el primer día, considero que terminó por revelar los conflictos y flaquezas que ocurren al interior de la organización pero que la exceden. La fragilidad de la comunidad quedó expuesta ante la baja convocatoria, probablemente reflejo de la falta de interés que pronosticó Juana, ya que las vías de difusión utilizadas (redes sociales y la difusión entre profesores/estudiantes) son los medios que usan habitualmente para convocar. En cuanto a quiénes estuvo dirigido, vimos que los asistentes quedaron prácticamente por fuera de las conversaciones, y no olvidemos la división exprofeso que se planteó en el comienzo entre quienes son miembros de la comunidad y quienes no (la mayoría de los que asistieron). Pienso que los profesionales buscaron orientar a través de contenidos preestablecidos a los huarpes, desconociendo las particularidades de la comunidad. Tal como contestó Claudia, respondían a lo solicitado por la autoridad de la comunidad pero, más allá de las buenas intenciones que 
puedan haber tenido, condujeron a la comunidad hacia una forma específica de identificación étnica (sobre la cual me explayaré más adelante) en un intento por reactivar el dominio por sobre la representación del movimiento huarpe y ampliar el alcance del mismo hacia otras provincias. Mientras que en el caso de la dirigencia huarpe, fue empleado como una estrategia para acceder a otro círculo, en una búsqueda hacia la reafirmación de su organización frente a otras y de la legitimidad de la autoridad ante sectores académicos y el gobierno de San Luis -una forma de reafirmar el trabajo de Juana como funcionaria indígena-. Como se evidenció en los debates surgidos, la gran mayoría de las comunidades vecinas no cuentan con el reconocimiento estatal de la forma que esta posee, empero, sí gozan de cierta legitimidad entre colectivos huarpes, por eso considero que el "fortalecimiento" no se busca solo al interior de la comunidad sino, también, hacia un otro.

\section{Día dos: Recetas para un etno-desarrollo garantizado}

Aquella jornada comenzó con la actividad propuesta por uno de los profesores el día anterior. Los asistentes debían llevar un listado sobre aspectos que considerasen amenazas y/o fortalezas de la comunidad, luego, entre todos, armarían una lista. La consigna se desprendió del denominado análisis FODA (fortalezas, oportunidades, debilidades y amenazas), una herramienta utilizada para diagnosticar estrategias a futuro.

Al comienzo hubo mayor participación, los asistentes compartieron lo que escribieron en sus hogares. Respecto de las falencias, una joven respondió que cuesta acostumbrarse a la vida en comunidad “donde todo es de todos". El profesor lo anotó en la pizarra. Juana preguntó si podría agregarse la falta de interés por capacitarse. El análisis FODA arrojó cuestiones vinculadas a las bondades o falencias siempre referidas a aspectos económicos, los profesores sintetizaron como negativo la falta de ofertas laborales y de servicios centrales, como un suministro fijo de agua potable y centros de salud, omitiendo quién o quiénes serían los responsables de ello. De manera positiva resaltaron el apoyo económico y político por parte del gobierno provincial. No se exteriorizaron cualidades ni debilidades en el plano cultural y/o espiritual, los pilares a "fortalecer".

Claudia, realizó un repaso por los temas tratados (situación del pueblo huarpe, derechos indígenas y patrimonio) e inauguró el cuarto eje del curso: "etnodesarrollo, significa cómo queremos caminar hacia adelante, eso que queremos producir” y señaló los pasos alcanzar el (etno) desarrollo:

Vamos a ver cómo mejorar la calidad de vida en términos de autosuficiencia. Esta fue la palabra que nos pidió Juana y esto es lo que estamos hablando en el FODA, es lo que genera empleo, arraigo. La autosuficiencia genera que estén capacitados para desarrollar servicios y productos y que no necesiten de planes sociales, como dijo ella (Juana). Estos términos son muy importantes porque es lo que tenemos que buscar: el etnodesarrollo y el buen vivir; a diferencia de las leyes de los no originarios donde se habla del desarrollo económico. 
Aquel día no se produjo ninguna discusión, la dinámica del curso se llevó adelante sin sobresaltos. Ante el tímido involucramiento de estos jóvenes en esta última parte, Claudia insistió en que el impulso debía surgir de ellos mismos: "ustedes tienen acá la historia del pueblo huarpe y no la historia contada por otro que vino, ustedes son la biblioteca, de ustedes va a salir el cosmo-conocimiento para el etnodesarrollo”. Aun así, el público continuó impávido. Pasado el mediodía se comunicó a los asistentes las actividades que deberían realizar posteriormente (en la escuela o en sus hogares) y que retirarían en un plazo a acordar. Por último, se informó que aquel material serviría de insumo para una publicación y en donde figurarían los asistentes ${ }^{12}$. Una vez presentadas las consignas se dio por finalizado este curso, tanto los profesores como los jóvenes emprendieron el regreso. En cuanto a las repercusiones, fueron bajas dentro de la comunidad. Al tratarse de un fin de semana largo pasaron unos días hasta que se retomó la actividad habitual y el taller no causó revuelo, fue enmarcada como una actividad de la escuela.

\section{Viejos/nuevos corolarios de (etno) desarrollo y cultura}

Hubo a lo largo del taller un constante ejercicio de autoridad por parte de los profesionales, como también de Juana, para con los asistentes. La audiencia fue la misma durante los dos días, los asistentes solo intervinieron cuando se les solicitó. De esta manera se reprodujo una relación jerárquica entre docente/alumno donde el profesor conduce la presentación, pregunta y evalúa (las respuestas eran receptadas mediante reforzadores positivos: "muy bien, jtiene un 10!"; "ni yo podría haberlo dicho mejor"). En ciertas instancias, se podría haber producido un intercambio más fructífero, por ejemplo, fue significativa la respuesta de la joven el último día cuando aludió a la dificultad que significó en lo cotidiano acostumbrarse a "compartir", ya que se imbrica a transformaciones sobrevenidas como parte del proceso de vivir en comunidad. Empero, su comentario fue obturado rápidamente por la intervención de Juana.

En cuanto al contenido del segundo día, resultó más llamativo: se evocaron términos como buen vivir, cosmovisión y etnodesarrollo para referirse a mundos otros suponiendo que solo existe una forma de ser ese otro, estableciendo que los pueblos originarios a priori gozan de una cultura otra. Me interesa reparar en la utilización de nociones como etnodesarrollo y el concepto de cultura que de esta se desprende. La primera fue evocada como medio y fin hacia una (auto) búsqueda en la medida que le permita a los mismos huarpes ser los responsables de su desarrollo económico. Por ejemplo, Claudia mencionó la importancia del valor agregado en la producción, incentivándolos a crear la marca huarpe (para la venta de tejidos, mermeladas y artesanías), lo que implicaría la transformación en mercancía de sus productos y prácticas culturales (COMAROFF; COMAROFF 2011: 41). En un intento de despojarlo de interés mercantil occidental, en tanto que se produciría -junto- con la "identidad".

Pues bien, el término etnodesarrollo alude a la capacidad de autogestión de grupos culturalmente diferenciados, donde la cultura "propia" adquiere un valor en sí (BONFIL BATALLA 1995, las comillas son propias). Como ya se dijo, la reivindicación de la diferencia

12 Hasta el momento no se ha avanzado en el escrito final, desconozco si hay intenciones de concretarlo. 
cultural hace un tiempo que impregnó agendas estatales y se manifiesta a través de programas y proyectos. Ahora, interesa subrayar esta idea de quienes creen estudiar sujetos con una cultura específica. La cual debe preservarse, fortalecerse y exhibirse como garantía de autenticidad (ESPÓSITO 2017: 189) en una coyuntura donde la etnicidad adquiere valor de cambio (COMAROFF; COMAROFF 2011). En esta sintonía, la cultura e identidad huarpe se esgrimieron como parte de una entelequia preestablecida, como sí simplemente "permaneciera". Por ejemplo, cuando Claudia les decía: "ustedes tienen acá la historia... de ustedes va a salir el cosmoconocimiento", apelando a la 'voluntad de continuidad' (BASCOPÉ 2009: 64). A diferencia de otros casos donde la cultura se torna objeto de disputa, se negocia y se redefine como parte del juego político (BASCOPÉ 2009; ESPÓSITO 2017), aquí los sentidos particulares que estos jóvenes otorgan a lo huarpe -y que levemente asomaron- quedaron atrapados en una evocación continua de cómo debe ser practicado/demostrado.

No es la intención aquí caer en la denuncia, si no volcarnos hacia una reflexión que considere a la identidad étnica como el efecto de relaciones de dominación históricamente situadas (BASCOPÉ 2009: 46). Vimos que se reinstaló la distinción entre "nosotros" (blancos, occidentales, universitarios) y los "otros", y desde este lugar la etnicidad se presentó como algo dado, contribuyendo a reificar la cultura como diferenciada. Dicha separación no solo lo convierte en un otro, ajeno y exótico, también lo vuelve nativo al ubicarlo en un marco de análisis diferente. Es decir, espacialmente encarcelado en esa otra cultura (GUPTA; FERGUSON 2008).

Sintetizando, en el taller se hizo palpable el uso de una visión esencialista, homogeneizante y reificante de la cultura huarpe, simplificando la realidad y pasando por alto el carácter político y producido de la identidad étnica. Así, pese a la baja convocatoria y a la escasa participación de los asistentes, estos se convirtieron en los potenciales poseedores de cultura y representantes de esta en un futuro cercano. Por tal motivo, fueron instruidos más que como producto -y productores- de historia, como testigos de la cultura huarpe.

Recapitulando, el primer día se evidenció la permanencia y reactualización de vínculos entre mediadores no indígenas y comunidades huarpes de la zona. Así como las diferencias entre comunidades y las condiciones actuales de reconocimiento, según las políticas indigenistas de cada provincia. En el segundo día, los matices multiculturales del discurso cobraron mayor protagonismo, esto nos habla de la consolidación de este grupo dentro de un espacio universitario alineado a programas y políticas estatales, en un territorio donde la presencia indígena ha cobrado una notoria visibilidad de un tiempo a esta parte, junto a su institucionalización. Por eso, a diferencia con unos años atrás, las discusiones no versaron acerca de quienes deben/pueden formar parte o no de las comunidades huarpes (SALDI 2012).

Con lo anterior quiero decir que el contexto dista de cómo era hace una década atrás, y por más que continúen operando estos agentes étnicos, las estrategias de los mismos se ven modificadas a causa de procesos locales y nacionales e internacionales. Lo cual se vio reflejado en los mecanismos discursivos y tácticas desplegadas que guardan relación directa con discursos de raigambre neoliberal, en línea con proyectos de desarrollo que se desprenden de diagramas de saber/poder ceñidos a una 'etnogubernamentalidad' (BOCCARA; AYALA 2011). Estos cambios suponen desafíos al interior de la política indígena, y en este contexto cobra mayor 
sentido el pedido que movilizó el armado del taller respecto de cómo continuar. En particular el contexto de San Luis donde el proceso de emergencia huarpe resultó característico en cuanto a la relación construida entre la comunidad huarpe y el estado provincial, que como vimos fue considerada "caso modelo" de reconocimiento.

\section{De alteraciones, diplomacia e idiotas}

Por último, quisiera plasmar una serie de reflexiones desde mi lugar como investigadora/etnógrafa. Comencé la escritura de este trabajo vehiculizada por un sentimiento incómodo que me rondó a largo de tal experiencia. Pues, paradójicamente, en el contexto del taller me costó situarme y quedé prácticamente inmóvil. Es por eso que me urge pensar en el lugar que ocupamos en tanto cientistas sociales en situaciones como las descriptas, donde entra a cuajar la pregunta por la alteridad, pudiendo correr el riesgo de inscribir la otredad como hecho y condición de los nativos. Considero necesario problematizar la responsabilidad que nos atañe como cientistas sociales en general y en particular desde el quehacer antropológico, en tal sentido me pregunto: ¿Es posible responder desde el lugar de antropólogos a lo solicitado por la cacique sin que las formas atenten contra la singularidad de los procesos mismos? ¿Cómo hacerlo sin que nuestra propia práctica continúe reproduciendo relaciones de dominación y violencia epistémica? ¿Cómo transformar estas relaciones asimétricas en ideas y prácticas conjuntas? Puesto que, si procuramos no reducir un grupo a una identidad cultural con el perjuicio de obturar el proceso de singularización, y por el contrario queremos denotar el carácter fabricado y relacional de la misma, cómo hacer para, en esa relación/creación, no caer en la 'intención de continuidad' que refiere Bascopé. En tanto que la identidad como socialmente construida es parte del sentido común de las ciencias sociales (BRIONES 2007), cómo hacer para repensar la relación antropólogo/nativo y abandonar el ideario de alteridad como etiqueta, plausible de ser medida por estándares académicos.

Comienzo por barajar algunas propuestas que evocan relaciones diplomáticas, dialécticas y más equitativas entre observador/observado. Como Latour (2014) que plantea un rol del investigador social similar a la del diplomático, capaz de lograr una mixtura entre investigación e intervención donde la cuestión del otro no se reduzca a "un otro posible" en tanto que hay más maneras de ser otro. Mientras que, Descola considera que la dominación y el conocimiento constituyen una doble pulsión indisoluble, y que la manera de contrarrestarla es apostando por una 'alterización equitativa' entre quienes somos alterados por la alteridad y el que la altera (DESCOLA 2018: 83). Por otro lado, Guattari y Rolnik (2013) realizan un llamado a los profesionales de lo social que se interesan en el discurso del otro y que se hayan en una posición clave y micropolítica, es que de su capacidad dependerá poder articular los agenciamientos de enunciación.

A la luz de estos autores, debemos aventurarnos a un trato más simétrico permitiéndonos afectarnos por las concepciones del otro (GOLDMAN 2006). Sugiero pensar en relaciones que sean conciliadoras y realmente capaces de articular saberes, en vez de acudir a categorías que invocan la pluralidad pero enmascaran una imposición. Es necesario que nos ocupemos de los modos de agenciamientos en los procesos de expresión, como plantean 
Guattari y Rolnik. Esto implica atender a las demandas que estos grupos nos presentan y entender la autenticidad que se les demanda, en una coyuntura donde los indígenas acuden a la universidad buscando herramientas para sus pueblos; donde ocupan y transitan espacios estatales. Además de abandonar el portavoz autorizado, se requiere que seamos capaces de reconocer a los interlocutores como legítimos actores políticos y no enjaularlos dentro de marcos de enunciación ligados a una alteridad determinada. Ahora, ¿Cómo plantear un diálogo diplomático y simétrico en contextos como el expuesto?

Pienso que podemos ejercitar el corrernos de posicionamientos encorsetados y encarar una negociación entre antropólogo y nativos desde el "no sabemos", dando lugar a la posibilidad de establecer una relación desde la "alteración" y con ello inaugurar instancias de creación y comunicación. Con tal motivo, retomo el llamado de Stengers a lo desconocido y su evocación a la figura del idiota ${ }^{13}$ como contrapuesta a la autoridad, en donde el primero, al no saber, hace presencia y clausura la posibilidad de sentirse autorizado de representar (2014: 14). Parafraseando a la autora, la propuesta no consiste en decir cómo debería ser, sino, hacer(nos) pensar y mascullar las inseguridades. En este sentido, es que considero al idiota como aquel que se desconcierta y desconoce. En un principio mi accionar en el taller se asemejó al de un idiota, como referí: sentí vergüenza de ser antropóloga y no saber qué hacer como tal, así como desconcierto al notar los efectos etnocentristas de la práctica. No obstante, esto desembocó en una forma tímida -y cómoda- de involucramiento. Aun así, el apremio por expresarme me siguió hasta aquí, me impulsó hacia la textualización con el propósito de objetivar y, más que eso, salirme de la quietud. Resumiendo, sugiero seamos un idiota diplomático para asumirnos en ese intersticio desconocido.

El desafío es también intentarlo sin desconocer las disputas de poder y las luchas por la representación, en el sentido político como cultural (ESCOLAR 2010). De modo que debemos ser cuidadosos al poner el foco en el carácter fabricado y relacional de la cultura ante el riesgo de desdibujar posibles asimetrías en la relación, es preciso resaltar la necesidad de comprometernos con un conocimiento situado (HARAWAY 1991). Por todo esto, considero sumamente necesario etnografiar los espacios a través de los cuales operan y se constituyen campos de poder entramados a fenómenos como el multiculturalismo; así como los modos por medio de los cuales profesionales e intermediarios se constituyen en portavoces legítimos. A la vez que animarnos a escribir desde lugares incómodos, este aspecto inquietamente y movilizador es parte del quehacer antropológico, apuesto por una antropología de lo vivido (QUIRÓS 2011) para elaborar herramientas teóricas para combatir los esencialismos, desde un lugar que no consista únicamente en apelar a un "uso estratégico" (SPIVAK 1987) de la identidad.

\section{Agradecimientos}

13 Refiere a un personaje literario de la obra de Dostoievski que Deleuze retoma para pensar el paradigma de la acción política (MENGUE 2013). Stengers (2014) se sirve de esta figura conceptual para argumentar su postura cosmopolítica, si bien no es ahí a donde quiero llegar, su trabajo ayuda a pensar en los dislocamientos, en posicionamientos teóricos otros que requieren un movimiento político. 
Agradezco a Marcio Goldman por incentivarme a publicar este trabajo, el cual surgió de un curso que él dictó en la ciudad de Córdoba. También a Diego Escolar, por su lectura atenta y enriquecedora. Por último, pero no menos importante, a la revista y a los evaluadores.

\section{Referencias}

BASCOPÉ, Joaquín. (2009). La invasión de la tradición. Lo mapuche en tiempos culturales. Santiago de Chile, Colibrís.

BOCCARA, Guillaume; BOLADOS, Paola. (2008). “¿Dominar a través de la participación? El neoindigenismo en el chile de la posdictadura”. In: Memoria Americana vol.16, n.2, p. 167196.

BONFIL BATALLA, Guillermo. (1995). "Etnodesarrollo: sus premisas jurídicas, políticas y de organización”. In: Obras escogidas de Guillermo Bonfil Batalla. INAH/INI: México, p.464-480.

BRIONES, Claudia. (2007). Teorías performativas de la identidad y performatividad de las teorías. In: Tabula Rasa vol.6, p.55-83.

BRIONES, Claudia. (2005). "Formaciones de alteridad: contextos globales, procesos nacionales y provinciales”. In: BRIONES, Claudia (Comp.). Cartografias Argentinas. Politicas indigenistas $y$ formaciones provinciales de alteridad. Buenos Aires: Antropofagia, p.9-36.

CALDERÓN ARCHINA, Aldana. (2016). “Reparación histórica' y 'municipalización': el caso de la comunidad huarpe de Guanacache, San Luis, Argentina”. Estudios en Antropología Social - Nueva Serie, vol.1, n.2.

COMAROFF, John; COMAROFF, Jean. (2011). Etnicidad S.A. Buenos Aires: Katz.

DELEUZE, Gilles. (1995). Conversaciones. Valencia: Pretextos.

DESCOLA, Philippe. (2018). “Filosofar, aunque de otra manera”. In: FLORENCIA, Tola (Ed.) Una antropología alterada por la alteridad: entrevistas Philippe Descola. Buenos Aires, Palabra Reversa.

ESCOLAR, Diego. (2010). “Acompañando al pueblo huarpe”. In: GORDILLO, Gastón; HIRSCH, Silvia (Comp.), Movilizaciones indígenas e identidades en disputas en la Argentina. Buenos Aires: Prometeo, p. 173-206.

ESCOLAR, Diego. (2007). Los dones étnicos de la nación. Identidades huarpes y modos de producción de soberanía. Buenos Aires: Prometeo.

ESPINOSA, Ezequiel. (2013). "El Estado y la (re)producción étnica en San Luis: La agenda de las Culturas Originarias y la comunalización del Pueblo Nación Ranquel”. En $X$ Reunión de Antropología del Mercosur, Argentina.

ESPÓSITO, Guillermina. (2017). La polis Colla. Tierras, comunidades y politica en la Quebrada de Humahuaca. Buenos Aires: Prometeo.

GOLDMAN, Marcio. (2006). Como funciona a democracia: uma teoria etnográfica da política. Rio de Janeiro, 7Letras, p.368.

GUATTARI, Felix; ROLNIK, Suely. (2013). Micropolitica: cartografias del deseo. Buenos Aires: Tinta limón. 
GUPTA, Akhil; FERGUSON, James. (2008). “Más allá de la 'cultura’: espacio, identidad y las políticas de la diferencia”. In: Antípoda, n.7, p.233-256.

HALE, Charles. (2002). "Does Multiculturalism Menace? Governance, Cultural Rights and the Politics of Identity in Guatemala”. In: Journal of Latin American Studies, vol. 34, n.3.

HARAWAY, Donna. (1991). Ciencia, cyborgs y mujeres. La reinvención de la naturaleza. Madrid: Ediciones Cátedra.

LATOUR, Bruno. (2014). ¿El cosmos de quién? ¿Qué cosmopolítica? Comentarios sobre los términos de paz de Ülrich Beck. In: Revista Pléyade 14, p.43-59.

MALINOWSKI, Bronislaw. (1986). Los argonautas del pacífico occidental. Barcelona: PlanetaAgostini.

MENGUE, Philippe. (2013). Faire l’idiot. La politique de Deleuze. Paris, Germina.

QUIRÓS, Julieta. (2011). El porqué de los que van. Peronistas y piqueteros en el Gran Buenos Aires (una antropología de la política vivida). Buenos Aires, Antropofagia.

SALDI, Leticia. (2012). "Procesos de comunalización y territorialización indígena: disputas, rupturas y alianzas en el caso huarpe (centro-oeste argentino)”. In: Cuadernos Interculturales, vol. 10, n.19. https://www.redalyc.org/comocitar.oa?id=55226435007

STENGERS, Isabelle. (2014). "La propuesta cosmopolítica”. In: Revista Pléyade, 14, p.17-41. SPIVAK, Gayatri.1987. In other worlds. Essays in Cultural Politics. New York: Methuen.

sobre la autora

\begin{abstract}
Aldana Calderón Archina
Es Licenciada en Antropología por la Universidad Nacional de Córdoba (UNC) y Doctoranda en Ciencias Antropológicas por la misma universidad. Es becaria doctoral del CONICET en el Instituto Argentino de Nivología, Glaciología y Ciencias Ambientales (IANIGLA). Además, se desempeña como docente en la Universidad Nacional de Cuyo en Mendoza.
\end{abstract}

Fecha de recepción 26/03/2020

Fecha de aprobación 20/11/2020 